\title{
Effects of rodent-induced land degradation on ecosystem carbon fluxes in an alpine meadow in the Qinghai-Tibet Plateau, China
}

\author{
F. Peng, Y. Quangang, X. Xue, J. Guo, and T. Wang
}

Key laboratory of desert and desertification, Cold and Arid Regions Environmental and Engineering Research Institute (CAREERI), Chinese Academy of Sciences (CAS), Lanzhou, China

Correspondence to: X. Xue (xianxue@1zb.ac.cn)

Received: 22 August 2014 - Published in Solid Earth Discuss.: 13 October 2014

Revised: 3 February 2015 - Accepted: 9 February 2015 - Published: 4 March 2015

\begin{abstract}
The widespread land degradation in an alpine meadow ecosystem would affect ecosystem carbon (C) balance. Biomass, soil chemical properties and carbon dioxide $\left(\mathrm{CO}_{2}\right)$ of six levels of degraded lands (D1-D6, according to the number of rodent holes and coverage) were investigated to examine the effects of rodent-induced land degradation on an alpine meadow ecosystem. Soil organic carbon (SOC), labile soil carbon (LC), total nitrogen (TN) and inorganic nitrogen $(\mathrm{N})$ were obtained by chemical analysis. Soil respiration $\left(R_{\mathrm{S}}\right)$, net ecosystem exchange (NEE) and ecosystem respiration (ER) were measured by a Li-Cor 6400XT. Gross ecosystem production (GEP) was the sum of NEE and ER. Aboveground biomass (AGB) was based on a linear regression with coverage and plant height as independent variables. Root biomass (RB) was obtained by using a core method. Soil respiration, ER, GEP and AGB were significantly higher in slightly degraded (D3 and D6, group I) than in severely degraded land (D1, D2, D4 and D5, group II). Positive values of $\mathrm{NEE}$ average indicate that the alpine meadow ecosystem is a weak $\mathrm{C}$ sink during the growing season. The only significant difference was in ER among different degradation levels. $R_{\mathrm{S}}$, ER and GEP were 38.2, 44.3 and $46.5 \%$ higher in group I than in group II, respectively. Similar difference of ER and GEP between the two groups resulted in an insignificant difference of NEE. Positive correlations of AGB with ER, NEE and GEP, and relatively small AGB and lower $\mathrm{CO}_{2}$ fluxes in group II, suggest the control of $\mathrm{AGB}$ on ecosystem $\mathrm{CO}_{2}$ fluxes. Correlations of RB with SOC, LC, TN and inorganic $\mathrm{N}$ indicate the regulation of $\mathrm{RB}$ on soil $\mathrm{C}$ and $\mathrm{N}$ with increasing number of rodent holes in an alpine meadow ecosystem in the permafrost region of the Qinghai-Tibet Plateau (QTP).
\end{abstract}

\section{Introduction}

Soil contains the largest ecosystem carbon (C) stock (Batjes, 1996). Widespread land degradation (Dregne, 2002), including land use change and soil and vegetation degradation, has resulted in severe soil $\mathrm{C}$ and nitrogen (N) loss (Wang et al., 2009; Parras-Alcántara et al., 2013), which is estimated to be 19-29 Pg C worldwide (Lal, 2001). Restoration of the degraded ecosystems, therefore, has a great potential to sequestrate $\mathrm{C}$ from the atmosphere (Lal, 2004) at an annual rate of 0.9-1.9 Pg C for a 25- to 50-year period in drylands (Lal, 2001).

Grassland stores about $15.2 \%$ of the terrestrial ecosystem vegetation and soil C stock (Ajtay, 1979). Either the aboveground vegetation (Fan et al., 2007) or the top $1 \mathrm{~m}$ of soil and root C stock (Yang et al., 2008) in an alpine meadow in the Qinghai-Tibet Plateau (QTP) account for a large proportion of those in grassland ecosystems in China (Ni, 2002). However, over one-third of the grassland in the QTP has been severely degraded due to climate change, grazing and road constructing since the 1990s (Ma et al., 1999), which has led to $1.8 \mathrm{Gg} \mathrm{C}$ loss in aboveground C stock from 1986 to 2000 (Wang et al., 2008). In addition to the vegetation C loss, land degradation could also result in decline in soil $\mathrm{C}$ and $\mathrm{N}$ (Wang et al., 2008; Wen et al., 2013), and consequently might alter net $\mathrm{C}$ balance in the alpine meadow (Li et al., 2011).

The primary factor causing "black soil type" degradation over the QTP is rodent grazing and burrowing (Ma et al., 1999). Rodent grazing activities trigger decline in biomass; lead to change in belowground biomass distribution, soil structure and microclimate; cause soil erosion and nutrient loss; and finally affect the ecosystem $\mathrm{C}$ balance (Li et al., 2011). Current studies about ecosystem $\mathrm{C}$ balance in alpine 


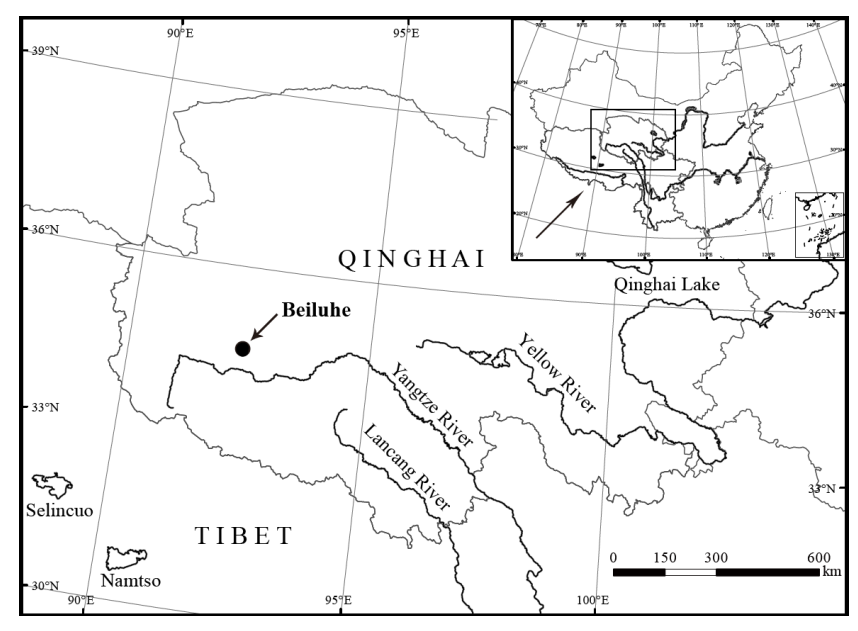

Figure 1. Location of the study area.

meadows focus on net ecosystem exchange (NEE) (Kato et al., 2004), inter-annual variation in NEE (Kato et al., 2006), soil respiration $\left(R_{\mathrm{S}}\right)$ and ecosystem respiration (ER) responses to experimental warming (Peng et al., 2014b; Luo et al., 2010; Lin et al., 2011). Effects of rodent-induced land degradation on ecosystem $\mathrm{CO}_{2}$ fluxes have rarely been investigated. Studies only examining the responses of $R_{\mathrm{S}}$ to land degradation (Zhang et al., 2010; J. Wang et al., 2007) cannot provide solid evidence for determining the response of ecosystem $\mathrm{C}$ balance. No field experiment has been conducted in the permafrost region of the QTP to investigate the effect of land degradation on NEE, a direct measure of the ecosystem $\mathrm{C}$ balance, and on its components: ER and gross ecosystem production (GEP). We conducted a field study to investigate (1) how the NEE and its components respond to rodent-induced land degradation, and (2) how biotic and abiotic factors affect those $\mathrm{CO}_{2}$ fluxes with land degradation processes in a Kobresia pygmaea-dominated alpine meadow in a permafrost area of the QTP.

\section{Materials and methods}

\subsection{Site description}

The study site is situated in the source region of the Yangtze River and in the middle of the QTP (Fig. 1, 92 $56^{\prime} \mathrm{E}$, $34^{\circ} 49^{\prime} \mathrm{N}$ ) with a mean altitude of $4635 \mathrm{~m}$ a.s.l. and a typical alpine climate. Mean annual temperature is $-3.8^{\circ} \mathrm{C}$ (2000-2010) with minimum mean monthly temperature of $-27.9^{\circ} \mathrm{C}$ in January and maximum mean of $19.2^{\circ} \mathrm{C}$ in July. Mean annual precipitation is $290.9 \mathrm{~mm}$ with $95 \%$ falling from May to October. Mean annual potential evaporation is $1316.9 \mathrm{~mm}$, mean annual relative humidity is $57 \%$ and mean annual wind velocity is $4.1 \mathrm{~m} \mathrm{~s}^{-1}$ (Lu et al., 2006). The study site is a winter-grazed range, dominated by alpine meadow vegetation: Kobresia capillifolia, Kobresia pygmaea and Carex moorcroftii, with a mean plant height of $5 \mathrm{~cm}$. Plant roots are mainly within the $0-20 \mathrm{~cm}$ soil layer, with average soil organic carbon (SOC) of $1.5 \%$. Soil development is weak and is alpine meadow soil (soil taxonomy in China, and Cryosols in World Reference Base (WRB) taxonomy; IUSS, 2006) with a mattic epipedon at approximately 0 $10 \mathrm{~cm}$ depth and an organic-rich layer at $20-30 \mathrm{~cm}$ (G. Wang et al., 2007). The parent soil material is of fluvio-glacial origin, and sand $(>0.05 \mathrm{~mm})$ content is about $95 \%$. Permafrost thickness observed near the experimental site is $30-70 \mathrm{~m}$, and the depth of the active layer is 1.5-3.5 $\mathrm{m}$ (Wu and Liu, 2004). However, the thickness of the active layer has been increasing at a rate of $3.1 \mathrm{~cm} \mathrm{yr}^{-1}$ since 1995 due to climatic warming (Wu and Liu, 2004).

\subsection{Experimental design and measurement protocol}

\subsubsection{Experimental design}

We selected six habitats with different number of rodent holes (NRHs) and community coverage in a mountain slope based on our filed observation. The habitats were sequenced D1-D6 from east to northeast. The distance between each habitat was about $200-300 \mathrm{~m}$. Two subplots $(2 \mathrm{~m} \times 4 \mathrm{~m})$ were set up in each habitat. The NRHs, coverage, plant height and major species in D1-D6 were shown in Table 1.

\subsubsection{Measurement protocol}

\section{Soil temperature}

Soil temperature at the depth of $5 \mathrm{~cm}$ was monitored by a thermo-probe attached to a Li-Cor 6400 (Lincoln, NE, USA) when measurements of $R_{\mathrm{S}}$, NEE and ER were conducted.

$\mathrm{CO}_{2}$ fluxes: a PVC collar $\left(80 \mathrm{~cm}^{2}\right.$ in area and $5 \mathrm{~cm}$ in height) was inserted $2-3 \mathrm{~cm}$ into soil permanently at the centre of each plot for measuring $R_{\mathrm{S}}$. The measuring procedure of $R_{\mathrm{S}}$ was similar to that reported in former studies (Peng et al., 2014b; Zhou et al., 2007). Ecosystem respiration and NEE were measured with a transparent chamber $(0.5 \times 0.5 \times 0.5 \mathrm{~m})$ attached to an infrared gas analyser $(\mathrm{Li}-$ Cor 6400, Lincoln, NE, USA). The method used was similar to that reported by Steduto et al. (2002) and Niu et al. (2008). Gross ecosystem production was the calculated as the sum of $\mathrm{NEE}$ and ER. Ecosystem $\mathrm{CO}_{2}$ fluxes were measured once a month from June to September in each plot.

\section{Soil sampling}

One soil sample was collected at the soil depth of $0-30 \mathrm{~cm}$ in each plot in June 2012.

\section{AGB and RB}

Aboveground biomass (AGB) was obtained from a step-wise linear regression, with AGB as the dependent variable, and 
Table 1. Features of different habitats, which are represented by different number of rodents holes (NRHs, deep and shallow), coverage, plant height $(H)$ and major plant species.

\begin{tabular}{lrrrrl}
\hline DD & $\begin{array}{r}\text { NRHs } \\
(\text { deep })\end{array}$ & $\begin{array}{r}\text { NRHs } \\
(\text { shallow })\end{array}$ & $\begin{array}{r}\text { Coverage } \\
(\%)\end{array}$ & $\begin{array}{r}H \pm \text { SE } \\
(\mathrm{cm})\end{array}$ & $\begin{array}{l}\text { Major } \\
\text { species }\end{array}$ \\
\hline D1 & 19 & 7 & 18 & $9.5 \pm 1.2$ & Carex moorcroftii \\
D2 & 5 & 13 & 35 & $7 \pm 0.7$ & Kobresia humilis, Kobresia pygmaea \\
D3 & 0 & 3 & 80 & $6.5 \pm 0.2$ & Kobresia pygmaea \\
D4 & 12 & 15 & 42 & $8 \pm 0.4$ & Carex moorcroftii, Kobresia pygmaea \\
D5 & 17 & 13 & 30 & $7.5 \pm 0.5$ & Carex moorcroftii, Kobresia pygmaea \\
D6 & 2 & 0 & 60 & $12 \pm 0.3$ & Carex moorcroftii \\
\hline
\end{tabular}

Table 2. Major devices, measuring procedure, specific feature of methods and equipments to conduct the measurement of soil chemical properties and ecosystem $\mathrm{CO}_{2}$ fluxes.

\begin{tabular}{llll}
\hline Items & Devices or procedure & Specific feature & Literature \\
\hline$T$ & 6000-09TC, Li-Cor, Utah, USA & A thermo-probe & \\
$R_{\mathrm{S}}$ & 6400-09, Li-Cor, Utah, USA & A collar $5 \mathrm{~cm}$ in depth & Zhou et al. (2007) \\
$\mathrm{ER}$ & 6400XT, Li-Cor, Utah, USA & A collar $50 \mathrm{~cm}$ in depth & Steduo et al. (2002), Niu et al. (2008) \\
$\mathrm{NEE}$ & 6400XT, Li-Cor, Utah, USA & A transparent chamber CO $\mathrm{C}_{2}$ gradient & Steduo et al. (2002), Niu et al. (2008) \\
$\mathrm{AGB}$ & A frame and a ruler & Linear regression & Xu et al. (2015) \\
$\mathrm{RB}$ & An auger & & Xu et al. (2015) \\
$\mathrm{SOC}$ & Walkley-Black method & & Walkley et al. (1947) \\
$\mathrm{TN}$ & Kjeldahl nitrogen method & & \\
$\mathrm{NH}$ & & \\
$\mathrm{LC}^{+}, \mathrm{NO}_{3}^{-}$ & Spectrometer & Spectrometer & Blair et al. (1995) \\
\hline
\end{tabular}

$T$ is the soil temperature at $5 \mathrm{~cm}$ depth; $R_{\mathrm{S}}$, soil respiration; ER, ecosystem respiration; NEE, net ecosystem exchange; AGB, aboveground biomass; RB, root biomass; SOC, soil organic carbon; $\mathrm{TN}$, total nitrogen; $\mathrm{NH}_{4}^{+}$and $\mathrm{NO}_{3}^{-}$, ammonia and nitrate nitrogen, respectively; LC, labile carbon.

coverage and plant height as independent variables (Peng et al., 2014b; Xu et al., 2015). Coverage of each plot was measured using a $10 \mathrm{~cm} \times 10 \mathrm{~cm}$ frame in four diagonally divided subplots replicated eight times in D1-D6 in June 2012. Plant height was measured 40 times by a ruler and averaged for each plot. Root biomass (RB) was obtained from soil samples that were air-dried for 1 week and passed through a sieve $(\Phi=2 \mathrm{~mm})$ to remove large particles. Roots were separated from the soil by washing, and fine roots was retrieved by sieve $(\Phi=0.25 \mathrm{~mm})$. Living roots were separated from dead roots by their colour and consistency (Yang et al., 2007), and the separated roots were dried at $75^{\circ} \mathrm{C}$ for $48 \mathrm{~h}$.

\section{Chemical analysis}

Soil organic carbon was analysed using the Walkley-Black method (Walkley, 1947). Total nitrogen was measured via the Kjeldahl method. Ammonia and nitrate $\mathrm{N}$ were measured colorimetrically through a spectrometer. Labile soil carbon (LC) measurement was carried out by the procedure by Moscatelli et al. (2007). Devices or procedure used in measuring above parameters, specific feature of the measurement were inclued in Table 2.

\subsection{Data analysis}

The statistical differences of soil temperature, $R_{\mathrm{S}}$, NEE, ER, GEP, SOC, total nitrogen (TN), inorganic N, C:N and biomass in D1-D6 were tested by the one-way ANOVA analysis at the $P<0.05$, and the Tukey test was used in doing the post hoc analysis for SOC, TN, inorganic N, $\mathrm{C}: \mathrm{N}$ and biomass. Previously to conduct the ANOVA, the Kolmogorov-Smirnov test and Levene test were used to test the normality and homogeneity of variance of the parameters. Monthly data of soil temperature, $R_{\mathrm{S}}$, NEE and GEP measured in each subplot from June to September were used in the analysis. Plots in D3 and D6 were ranked as group I, and those in D1, D2, D4 and D5 were considered group II because the total NRHs in D3 and D6 was much lower than that in D1, D2, D4 and D5. The statistical significance of $\mathrm{CO}_{2}$ fluxes between the two groups was also tested by one-way ANOVA analysis. The monthly differences in $\mathrm{CO}_{2}$ fluxes were analysed by repeated ANOVA. Relationships of $R_{\mathrm{S}}$, NEE and ER with soil temperature, ABG, RB and TN or inorganic $\mathrm{N}$ were analysed by linear regression analyses. Pearson correlation analysis was used to investigate the relationships of NRHs with soil chemical properties and biomass. The linear regression and Pearson correlation were considered significant with $P<0.05$. Soil respiration, NEE and ER 
data were the averages of 4 months in D1-D6 when conducting the correlation analysis. All the analyses were conducted in SPSS 16.0 for Windows.

\section{Results}

\subsection{Soil temperature}

Soil temperature at $5 \mathrm{~cm}$ depth maximized in July (Fig. 2) and average soil temperature of the 4 months had no significant difference $(P>0.05)$ among treatments. The monthly average soil temperature was about $9.6-12.4^{\circ} \mathrm{C}$ from D1 to D6. Soil temperature also had no significant difference between group I and II.

\subsection{Soil chemical properties and biomass}

Soil organic carbon, LC, TN, ammonia $\mathrm{N}$ and $\mathrm{RB}$ were higher in D2 than in other habitats (Table 3). AGB was higher in D3 and D6 than in others. Soil organic carbon, LC, TN and inorganic $\mathrm{N}\left(\mathrm{NH}_{4}^{+}-\mathrm{N}\right.$ and $\left.\mathrm{NO}_{3}^{-}-\mathrm{N}\right)$ had no obvious trend with the increasing NRHs, whereas AGB was negatively correlated with the NRHs $(r=-0.89, P<0.05)$.

\subsection{Soil respiration, net ecosystem exchange, ecosystem respiration and gross ecosystem production}

Repeated one-way ANOVA showed the significant seasonal change in $R_{\mathrm{S}}(P<0.01)$, ER $(P<0.05)$, NEE $(P<0.01)$ and GEP $(P<0.01)$. The maximum $R_{\mathrm{S}}$ and ER were in July (Fig. 3a, b), whereas the maximum NEE and GEP were in June (Fig. 3c, d). Growing season average $R_{\mathrm{S}}$ and NEE had no significant difference in D1-D6, while ER and GEP were marginally higher in D3 and D6 than in others (Table 4). Soil respiration, ER and GEP were significantly higher in group I than in group II $(P<0.05)$.

\subsection{Relationship of $R_{\mathrm{s}}$, ER and NEE with soil temperature, soil nitrogen and biomass}

Ecosystem $\mathrm{CO}_{2}$ fluxes had no obvious relationship with soil temperature (Fig. 4a), soil inorganic N (Fig. 4b) and RB (Fig. 4d), while they correlated positively with AGB, with the steepest regression slope in $R_{\mathrm{s}}$, followed by ER and NEE (Fig. 4c).

\section{Discussion}

\subsection{C and N loss}

Soil organic carbon, LC, TN and inorganic $\mathrm{N}$ were only significantly higher in D2 in our study (Table 3). The results indicate that $\mathrm{C}$ and $\mathrm{N}$ loss induced by rodent activities were different, with nutrient loss associated with desertification and wind erosion in temperate grassland (Zhang et al., 2010) or

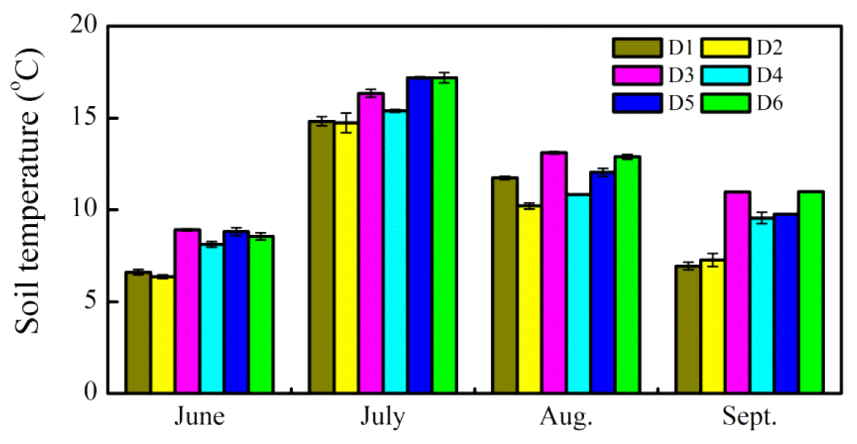

Figure 2. Soil temperature in each degradation level (D1-D6) from June to September. Error bars represent the standard error for D1D6 in each month.

in the alpine meadow ecosystem (Xue et al., 2009). Soil C and $\mathrm{N}$ loss can occur in degraded land by (1) reducing vegetative growth and exposing the soil surface to wind and water erosion, and by (2) reducing the return of litter to soil (Nunes et al., 2012). Higher AGB in D3 and D6 (Table 3) suggests more litter returning to the soil, but more ecosystem $\mathrm{CO}_{2}$ emission from soil in terms of higher $R_{\mathrm{s}}$ could be the reason for lower SOC, LC and TN in D3 and D6. Positive correlation between $\mathrm{AGB}$ and $R_{\mathrm{S}}$ indicates that decomposition of fresh litter from AGB might be the major component of $R_{\mathrm{S}}$ in the alpine meadow. The highest RB in D2 in spite of lower AGB compared with that in D3 and D6 (Table 3) provides evidence that $\mathrm{RB}$ is the major source of soil $\mathrm{C}$ and $\mathrm{N}$ in the alpine meadow ecosystem. The results was similar to a study where soil $\mathrm{C}$ and $\mathrm{N}$ storage increases were positively correlated with the increase of belowground biomass allocation with grazing pressure (Li et al., 2011).

\section{2 $\mathrm{CO}_{2}$ fluxes}

Soil temperature explains most of the temporal variation (Peng et al., 2014a), but RB determines the spatial variation in $R_{\mathrm{S}}$ over the QTP (Geng et al., 2012). The lack of an obvious relationship between $R_{\mathrm{S}}$ and soil temperature (Fig. 4a) suggests other factors might be involved in controlling the temporal variation in $R_{\mathrm{S}}$ in degraded land. Significant reduction of $R_{\mathrm{S}}$ only appears on the severely degraded alpine meadow level (Zhang et al., 2010). $R_{\mathrm{S}}$ being lower in group I than in group II (1) supports the above finding because community coverage in D1, D2, D4 and D5 (Table 1) conforms to the standard of the severely degraded alpine meadow (Xue et al., 2009) and (2) indicates the controlling effect of biomass on $R_{\mathrm{S}}$ in degraded land induced by rodent activities. Soil respiration is composed of autotrophic respiration from plant roots and their symbionts, and heterotrophic respiration from litter and SOC decomposition (Hanson et al., 2000). Aboveground biomass and dead roots are the major sources of alpine meadow litter (Sun and Wang, 2008), and SOC abates due to the decreasing litter input into soil as a result of lower 
Table 3. Soil organic carbon (SOC), labile soil carbon (LC), total nitrogen (TN), inorganic nitrogen $\left(\mathrm{NH} 4^{+}-\mathrm{N}\right.$ and $\left.\mathrm{NO} 3^{-}-\mathrm{N}\right)$, aboveground biomass (AGB) and root biomass (RB) in different sites (D1-D6) and results ( $F$ values) of one-way ANOVA analysis.

\begin{tabular}{|c|c|c|c|c|c|c|c|c|}
\hline DD & $\begin{array}{l}\text { SOC } \\
\left(\mathrm{g} \mathrm{kg}^{-1}\right)\end{array}$ & $\begin{array}{l}\mathrm{LC} \\
\left(\mathrm{g} \mathrm{kg}^{-1}\right)\end{array}$ & $\begin{array}{l}\mathrm{TN} \\
\left(\mathrm{mg} \mathrm{kg}^{-1}\right)\end{array}$ & $\begin{array}{l}\mathrm{NH}_{4}^{+} \_\mathrm{N} \\
\left(\mathrm{mg} \mathrm{kg}^{-1}\right)\end{array}$ & $\begin{array}{l}\mathrm{NO}_{3}^{-}{ }_{-} \mathrm{N}^{-1} \\
\left(\mathrm{mg} \mathrm{kg}^{-1}\right)\end{array}$ & $\begin{array}{l}\text { AGB } \\
\left(\mathrm{g} \mathrm{m}^{-2}\right)\end{array}$ & $\begin{array}{l}\mathrm{RB} \\
\left(\mathrm{kg} \mathrm{m}^{-2}\right)\end{array}$ & $\mathrm{C}: \mathrm{N}$ \\
\hline D1 & $4.91 \pm 0.13 b$ & $1.21 \pm 0.13 b$ & $0.44 \pm 0.02 b$ & $8.21 \pm 0.32 b$ & $4.16 \pm 0.62 \mathrm{a}$ & 149 & $3.8 \pm 0.06 c$ & $11.2 \pm 0.7 \mathrm{ab}$ \\
\hline D2 & $8.70 \pm 1.19 a$ & $2.12 \pm 0.31 \mathrm{a}$ & $0.75 \pm 0.10 \mathrm{a}$ & $13.11 \pm 1.23 \mathrm{a}$ & $3.81 \pm 0.51 \mathrm{ab}$ & 145 & $13.8 \pm 3.5 \mathrm{a}$ & $11.5 \pm 0.2 \mathrm{ab}$ \\
\hline D3 & $5.02 \pm 1.01 \mathrm{~b}$ & $1.23 \pm 0.29 b$ & $0.46 \pm 0.11 \mathrm{ab}$ & $8.54 \pm 1.00 \mathrm{~b}$ & $2.31 \pm 0.38 b c$ & 272 & $11.3 \pm 1.3 \mathrm{a}$ & $10.9 \pm 0.3 \mathrm{a}$ \\
\hline D4 & $3.95 \pm 0.62 b$ & $1.28 \pm 0.34 b$ & $0.36 \pm 0.05 \mathrm{ab}$ & $7.56 \pm 1.39 b$ & $2.62 \pm 0.24 b c$ & 189 & $6.0 \pm 1.5 b$ & $10.8 \pm 0.3 b$ \\
\hline D5 & $3.77 \pm 0.32 b$ & $0.9 \pm 0.09 \mathrm{~b}$ & $0.38 \pm 0.03 b$ & $9.38 \pm 1.33 b$ & $1.98 \pm 0.21 \mathrm{c}$ & 141 & $6.1 \pm 0.9 \mathrm{~b}$ & $10.1 \pm 0.2 b$ \\
\hline D6 & $3.41 \pm 0.35 b$ & $0.83 \pm 0.04 b$ & $0.34 \pm 0.02 b$ & $8.08 \pm 0.76 b$ & $2.64 \pm 0.10 \mathrm{bc}$ & 336 & $5.7 \pm 0.3 b$ & $9.9 \pm 0.4 b$ \\
\hline$F, P$ value & $F=11.05, P<0.01$ & $F=7.9, P<0.01$ & $F=5.9, P<0.01$ & $F=5.5, P<0.01$ & $F=7.5, P<0.01$ & & $F=15.7, P<0.01$ & $F=4.8, P=0.012$ \\
\hline
\end{tabular}

The values in the table were the average and standard error of soil samples at each site. Different letters in each column stands for significant difference of at $P<0.05$ level, $n=4$.
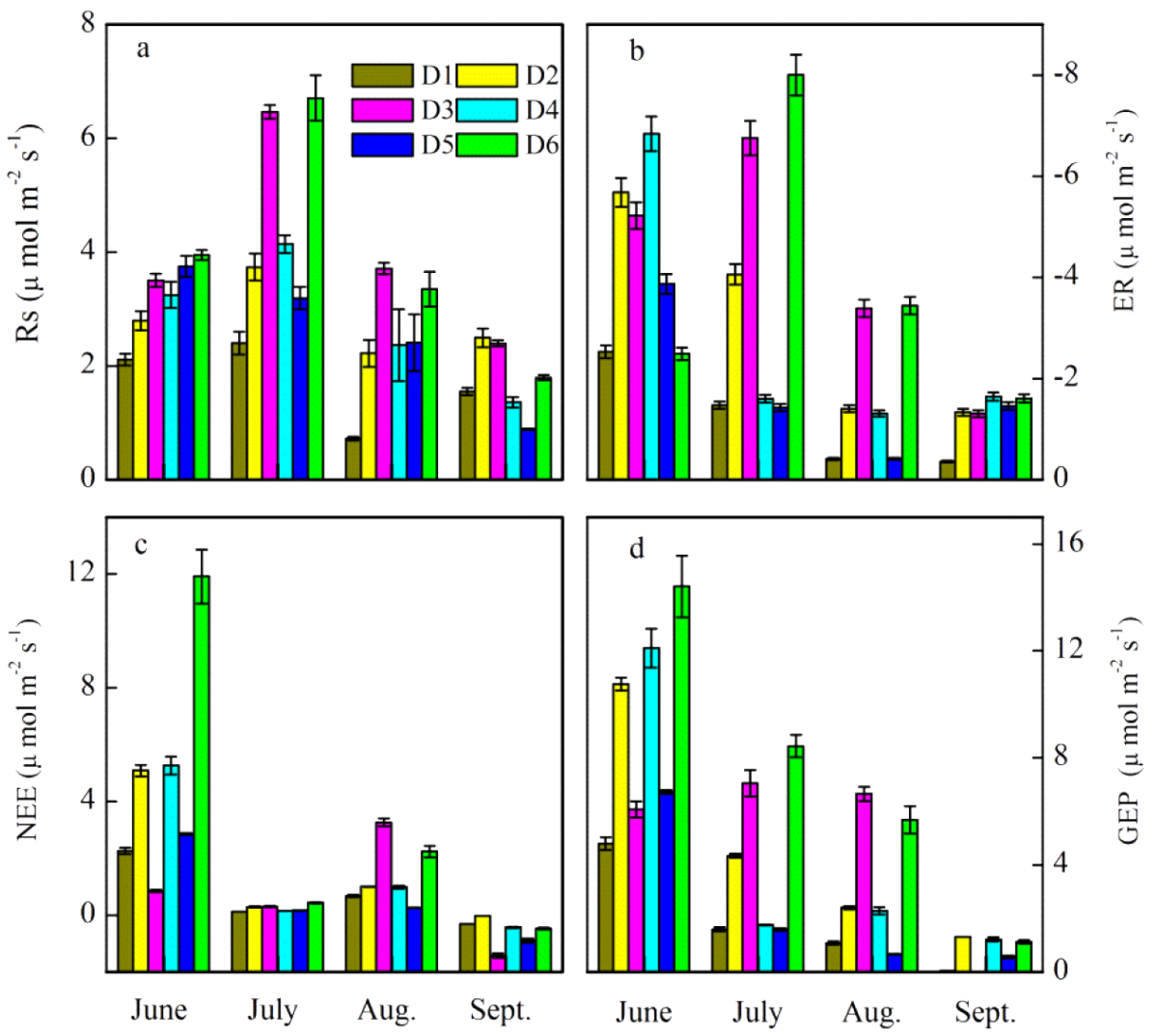

Figure 3. Monthly soil respiration $\left(R_{\mathrm{S}}, \mathbf{a}\right)$, ecosystem respiration (ER, b), net ecosystem exchange (NEE, $\mathbf{c}$ ) and gross ecosystem production (GEP, d) among different degradation levels from June to September. Values in the bars were the average of four replicates (two replicates in two subplots), and error bars are standard errors.

AGB and plant detritus (Wang et al., 2009; Wen et al., 2013). $\mathrm{RB}, \mathrm{SOC}$ and LC being lower yet AGB being higher in D3 and D6 than in D1 and D2 (Table 3) implies that AGB is the major controlling factor of $R_{\mathrm{S}}$ with the development of land degradation, which is proved by the positive correlation between $R_{\mathrm{s}}$ and AGB (Fig. 4c). In disturbed ecosystems, competition among microorganisms induces the microbes to use more $\mathrm{C}$ energy for cell integrity and maintenance (Moscatelli et al., 2007), and the consequently higher respiration quotient (Nunes et al., 2012) could contribute to the insignificant change in $R_{\mathrm{S}}$ with development of land degradation.
Ecosystem respiration comprises of respiration of AGB and $R_{\mathrm{S}}$ (Zhang et al., 2009). Higher $R_{\mathrm{S}}$ therefore could be one reason for the higher ER in D3 and D6. Lower relative difference in $R_{\mathrm{S}}(38.2 \%)$ than in ER $(44.5 \%)$ between the two groups suggests the influence of other factors like AGB on ER difference, which is supported by the positive correlation between ER and AGB (Fig. 4c).

The highest net photosynthesis in June in the alpine meadow ecosystem (Yi et al., 2000) justifies the maximum GEP in June (Fig. 3d). Sedge percentage will decrease and forb percentage increase with the development of land degra- 

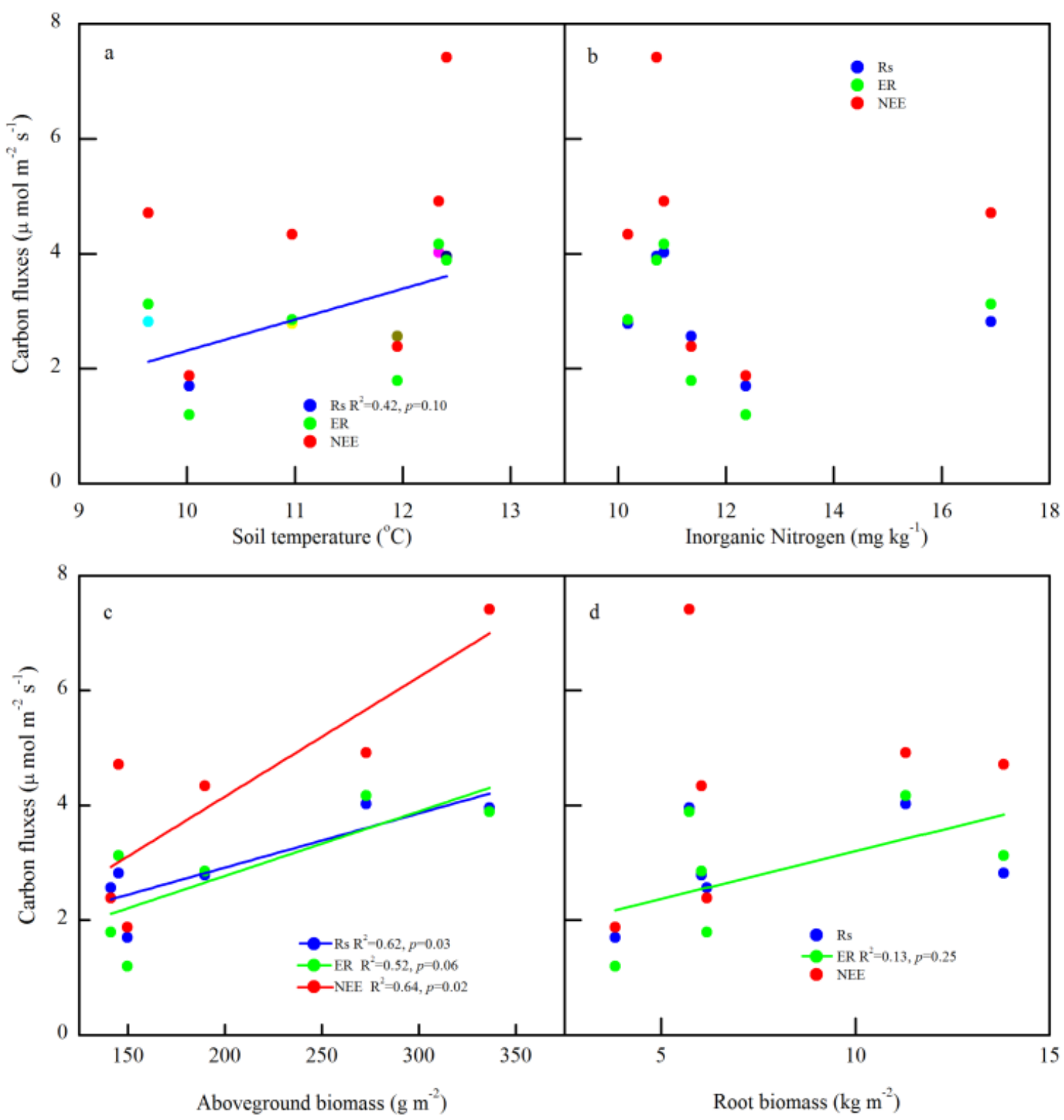

Figure 4. Linear regressions of $\mathrm{CO}_{2}$ fluxes (soil respiration, $R_{\mathrm{S}}$; ecosystem respiration, ER; net ecosystem exchange, NEE) with soil temperature (a), inorganic nitrogen (b), aboveground biomass (c) and root biomass (d). $R_{\mathrm{S}}$, ER and NEE data were the average of four measurements from June to September within two subplots; inorganic nitrogen and root biomass $(0-30 \mathrm{~cm})$ were derived from soil samples at $0-30 \mathrm{~cm}$ depth in June.

dation (Liu et al., 2008). The relatively higher net photosynthetic rate of forb species (Polygonum viviparum Linn.) than that of sedge species (Carex atrofusca Schkuhr, unpublished data) and higher AGB might compensate for the effect of species composition change on GEP due to the positive correlation between GEP and AGB $(r=0.84, P<0.05)$ in the current study.

The maximum NEE in June is a result of the highest GEP and lower ER in this time (Fig. 3). Positive average NEE (Fig. 3c) indicates alpine meadow is weak $\mathrm{C}$ sink in the growing season. The insignificant difference of NEE in the two groups (Table 4) might be the result of the corresponding change of ER ( $44.5 \%$ higher in group I than in group II) and GEP ( $46.5 \%$ higher in group I than in group II).

\subsection{Implication of the soil $\mathrm{C}$ dynamics}

The insignificant difference in NEE among different degradation levels suggests that SOC loss (in D1, D4 and D5) with land degradation is not a direct result of changes in net $\mathrm{C}$ uptake and emission. The higher SOC, LC and TN in D2 with more NRHs, and the positive correlation between RB and 
Table 4. Results ( $F$ values) of ANOVA on the effect of land degradation on soil respiration $\left(R_{\mathrm{S}}\right)$, ER (ecosystem respiration), NEE (net ecosystem exchange) and GEP (gross ecosystem respiration).

\begin{tabular}{rrrrrrrrr}
\hline & \multicolumn{4}{c}{ D1-D6 } & \multicolumn{4}{c}{ Group I and group II } \\
\hline & $R_{\mathrm{S}}$ & ER & NEE & GEP & $R_{\mathrm{S}}$ & ER & NEE & GEP \\
$F$ & 1.69 & 2.64 & 1.35 & 2.27 & 7.41 & 8.21 & 1.59 & 6.01 \\
$P$ & 0.12 & $\mathbf{0 . 0 4}$ & 0.26 & 0.06 & $\mathbf{0 . 0 1}$ & $\mathbf{0 . 0 0 6}$ & 0.21 & $\mathbf{0 . 0 2}$
\end{tabular}

Group I includes D3 and D6, while group II includes D1, D2, D4 and D5. Numbers in bold stand for the statistical significance at the $P<0.05$ level.

SOC suggest that other dynamics associated with land degradation, like species composition (W. Li et al., 2011) and C allocation between AGB and RB change (G. Li et al., 2011), might be involved in the soil $\mathrm{C}$ and $\mathrm{N}$ dynamics in degraded land in the alpine meadow ecosystem (Zhang et al., 2010).

\section{Conclusions}

Soil respiration, ER and GEP all decreased with increasing NRHs. The corresponding change in ER and GEP leads to insignificant change in NEE. All the ecosystem $\mathrm{CO}_{2}$ fluxes are primarily affected by AGB. SOC and soil nutrient change in degraded land is not a direct result of the response of net ecosystem $\mathrm{C}$ balance to land degradation. Other processes like species composition and above- and belowground biomass allocation might play a role in the soil $\mathrm{C}$ dynamic with development of land degradation.

Acknowledgements. The authors thank Yongzhi Liu, Hanbo Yun, Guilong Wu and Yuanwu Yang for their help in setting up the field experiment. Financial support came from the National Natural Science Foundation of China (41301211, 41201195 and 41301210); the Foundation for Excellent Youth Scholars of CAREERI, CAS (Y351191001); and the Chinese Academy of Sciences (Hundred Talents Program).

Edited by: P. Pereira

\section{References}

Ajtay, G. L.: Terrestrial primary production and phytomass: The global carbon cycle, John wiley sons, Chichester, 1979.

Batjes, N. H.: Total carbon and nitrogen in the soils of the world, European J. Soil Sci., 47, 151-163, 1996.

Dregne, H. E.: Land degradation in the drylands, Arid Land Res. Manage., 16, 99-132, 2002.

Fan, J. W., Zhong, H. P., Harris, W., Yu, G. R., Wang, S. Q., Hu, Z. M., and Yue, Y. Z.: Carbon storage in the grasslands of China based on field measurements of above- and below-ground biomass, Clim. Change, 86, 375-396, doi:10.1007/s10584-0079316-6, 2008.
Geng, Y., Wang, Y., Yang, K., Wang, S., Zeng, H., Baumann, F., Kuehn, P., Scholten, T., and He, J. S.: Soil Respiration in Tibetan Alpine Grasslands: Belowground Biomass and Soil Moisture, but Not Soil Temperature, Best Explain the Large-Scale Patterns, PLoS ONE, 7, e34968, doi:10.1371/journal.pone.0034968, 2012.

Hanson, P. J., Edwards, N. T., Garten, C. T., and Andrews, J. A.: Separating root and soil microbial contributions to soil respiratin: a review of methods and observations, Biogeochemistry, 48, 115-146, 2000.

Kato, T., Tang, Y., Gu, S., Cui, X., Hirota, M., Du, M., Li, Y., Zhao, $\mathrm{X}$., and Oikawa, T.: Carbon dioxide exchange between the atmosphere and an alpine meadow ecosystem on the Qinghai-Tibetan Plateau, China, Agr. Forest Meteorol., 124, 121-134, 2004.

Kato, T., Tang, Y., Gu, S., Hirota, M., Du, M., Li, Y., and Zhao, $\mathrm{X}$.: Temperature and biomass influences on interannual changes in $\mathrm{CO}_{2}$ exchange in an alpine meadow on the Qinghai-Tibetan Plateau, Global Change Biol., 12, 1285-1298, 2006.

Lal, R.: Potential of desertification control to sequester carbon and mitigate the greehouse effect, Clim. Change, 51, 35-72, 2001.

Lal, R.: Soil carbon sequestration impacts on global climate change and food security, Science, 304, 1623-1626, 2004.

Li, G., Liu, Y., Frelich, L. E., and Sun, S.: Experimental warming induces degradation of a Tibetan alpine meadow through trophic interactions, J. Appl. Ecol., 48, 659-667, 2011.

Li, W., Huang, H. Z., Zhang, Z. N., and Wu, G. L.: Effects of grazing on the soil properties and $\mathrm{C}$ and $\mathrm{N}$ storage in relation to biomass allocation in an alpine meadow, J. Soil Sci. Plant Nutr., 11, 27-39, 2011.

Lin, X. W., Zhang, Z. H., Wang, S. P., Hu, Y. G., Xu, G. P., Luo, C. Y., Chang, X. F., Duan, J. C., Lin, Q. Y., Xu, B., Wang, Y. F., Zhao, X. Q., and Xie, Z. B.: Response of ecosystem respiration to warming and grazing during the growing seasons in the alpine meadow on the Tibetan plateau, Agr. Forest Meteorol., 151, 792802, 2011.

Liu, X. N., Sun, J. L., Sun, D. G., Pu, X. P., and Xu, G. P.: A study on the community structure and plant diversity of alpine meadow under differetn degrees of degradation in the Eastern Qilian Mountains, Ac. Pratacult. Sinica, 17, 1-11, 2008.

Lu, Z., Wu, Q., Yu, S., and Zhang, L.: Heat and water difference of active layers beneath different surface conditions near Beiluhe in Qinghai-Xizang Plateau, J. Glaciol. Geogryol., 28, 642-647, 2006.

Luo, C. Y., Xu, G. P., Chao, Z. G., Wang, S. P., Lin, X. W., Hu, Y. G., Zhang, Z. H., Duan, J. C., Chang, X. F., Su, A. L., Li, Y. N., Zhao, X. Q., Du, M. Y., Tang, Y. H., and Kimball, B. A.: Effect of warming and grazing on litter mass loss and temperature sensitivity of litter and dung mass loss on the Tibetan plateau, Glob. Change Biol., 16, 1606-1617, 2010.

Ma, Y. S., Lang, B. N., and Wang, Q. J.: Review and prospect of the study on black soil type deteriorated grassland, Pratacul. Sci., 16, 5-9, 1999.

Moscatelli, M. C., Tizio, D., Marinari, A., and Grego, S.: Microbial indicators related to soil carbon in Mediterranean land use systems, Soil Till. Res., 97, 51-59, 2007.

$\mathrm{Ni}$, J.: Carbon storage in grasslands of China, J. Arid Environ., 20, 205-211, 2002. 
Niu, S., Wu, M., Han, Y., Xia, J., LI, L., and Wan, S.: Watermediated responses of ecosystem carbon fluxes to climatic change in a temperate steppe, New Phytol., 177, 209-219, 2008.

Nunes, J. S., Araujo, A. S. F., Nunes, L. A. P. L., Lima, L. M., Carneiro, R. F. V., Salviano, A. A. C., and Tsai, S. M.: Impact of land degradation on soil microbial biomass and activity in Northeast Brazil, Pedosphere, 22, 88-95, 2012.

Parras-Alcántara, L., Martín-Carrillo, M., and Lozano-García, B.: Impacts of land use change in soil carbon and nitrogen in a Mediterranean agricultural area (Southern Spain), Solid Earth, 4, 167-177, doi:10.5194/se-4-167-2013, 2013.

Peng, F., Xue, X., You, Q. G., Zhou, X. H., and Wang, T.: Warming effects on carbon release in a permafrost area of Qinghai-Tibet Plateau, Environ. Earth Sci., 73, 57-66, doi:10.1007/s12665014-3394-3, 2014a.

Peng, F., You, Q., Xu, M., Guo, J., Wang, T., and Xue, X.: Effects of Warming and Clipping on Ecosystem Carbon Fluxes across Two Hydrologically Contrasting Years in an Alpine Meadow of the Qinghai-Tibet Plateau, PLoS ONE, 9, e109319, doi:10.1371/journal.pone.0109319, 2014b.

Steduto, P., Çetinkökü, Ö., Albrizio, R., and Kanber, R.: Automated closed-system canopy-chamber for continuous field-crop monitoring of $\mathrm{CO}_{2}$ and $\mathrm{H}_{2} \mathrm{O}$ fluxes, Agr. Forest Meteorol., 111, 171186, 2002.

Sun, X. D. and Wang, Y. L.: Difference of biomass and soil nutrition in alpine cold meadow of different degraded degree, Chin. Qinghai J. Animal Veterin. Sci., 38, 6-8, 2008.

Walkley, A.: A critical examination of a rapid method for determining organic carbon in soils-effect of variations in digestion conditions and of inorganic soil constituents, Soil Science, 63, 251-264, 1947.

Wang, G., Wang, Y., Li, Y., and Cheng, H.: Influences of alpine ecosystem responses to climatic change on soil properties on the Qinghai-Tibet Plateau, China, CATENA, 70, 506-514, 2007.

Wang, G., Li, Y., Wang, Y., and Wu, Q.: Effects of permafrost thawing on vegetation and soil carbon losses on the Qinghai-Tibet Plateau, China, Geoderma, 143, 143-152, 2008.

Wang, J., Wang, G., Wang, Y., and Li, Y.: Influences of the degradation of swamp and alpine meadows on $\mathrm{CO}_{2}$ emission during growing season on the Qinghai-TIbet plateau, Chinese Sci. Bull., 52, 2565-2574, 2007.
Wang, W. Y., Wang, Q. J., and Lu, Z. Y.: Soil organic carbon and nitrogen content of density fractions and effect of meadow degradation to soil carbon and nitrogen of fractions in alpine Kobresia meadow, Sci. China Series D-Earth Sci., 52, 660-668, 2009.

Wen, L., Dong, S., Li, Y., Wang, X., Li, X., Shi, J., and Dong, Q.: The impact of land degradation on the $\mathrm{C}$ pools in alpine grasslands of the Qinghai-Tibet Plateau, Plant Soil, 368, 329-340, 2013.

Wu, Q. B. and Liu, Y. Z.: Ground temperature monitoring and its recent change in Qinghai-Tibet Plateau, Cold Reg. Sci. Technol., 38, 85-92, 2004.

Xu, M. H., Peng, F., You, Q. G., Guo, J., Tian, X. F., Xue, X., and Liu, M.: Year-round warming and autumnal clipping lead to downward transport of root biomass, carbon and total nitrogen in soil of an alpine meadow, Environ. Experiment. Bot., 109, 54-62, 2015.

Xue, X., Guo, J., Han, B. S., Sun, Q. W., and Liu, L. C.: The effect of warming and permafrost thaw on desertification in the QinghaiTibet Plateau, Geomorphology, 108, 182-190, 2009.

Yang, Y., Ma, W., Mohammat, A., and Fang, J.: Storage,patterns and controls of soil nitrogen in China, Pedosphere, 17, 776-785, 2007.

Yang, Y. H., Fang, J. Y., Tang, Y. H., Ji, C. J., Zheng, C. Y., He, J. S., and Zhu, B.: Storage, patterns and controls of soil organic carbon in the Tibetan grasslands, Glob. Change Biol., 14, 15921599, 2008.

Yi, X. F., Pen, G. Y., Shi, S. B., and Han, F.: Seasonal variation in photosynthesis of Kobresia humilis population and community at Haibei alpine meadow, Grassland China, 1, 12-15, 2000.

Zhang, F., Wang, T., Xue, X., Han, B. S., Peng, F., and You, Q. G.: The responses of soil $\mathrm{CO}_{2}$ to desertification on alpine meadow in the Qinghai-Tibet Plateau, Environ. Earth Sci., 60, 349-358, 2010.

Zhou, X. H., Wan, S. Q., and Luo, Y. Q.: Source components and interannual variability of soil $\mathrm{CO}_{2}$ efflux under experimental warming and clipping in a grassland ecosystem, Glob. Change Biol., 13, 761-775, 2007. 